\title{
A Study of Practices and Outcomes of HRM in Pakistan
}

\author{
DR. SAIMA BATOOL \\ Chairperson and Assistant Professor \\ Qurtuba University of Science and Information Technology, Peshawar \\ dr.saimabatool90@yahoo.com \\ YASIR KHAN \\ Ph.D Scholar, Qurtuba University of Science and Information Technology, Peshawar \\ yasirok62@yahoo.com \\ MUHAMMAD TAHIR \\ Business Administration Department, Iqra National University, Peshawar, Pakistan. \\ tahirkhanzaee@gmail.com \\ MUHAMMD IDRIS \\ Assistant Professor, Department of Education \\ Abdul Wali Khan University, Mardan \\ midrees@awkum.edu.pk
}

\begin{abstract}
HRM is capable of employee's development and enhanced organizational competitiveness, thus it can contribute positively for developing countries. However, there is poor understanding and limited research about HRM in developing countries context. Pakistan also embraced HRM almost a decade ago; however, the experience is producing mix results. The current study is carried out with the objective to assess the HRM Practices and the HRM outcomes in Pakistan. The study utilizing semi-structured interviews and data was collected from sixty HR Personnel working in various organizations. Key findings of the study are that despite implementation of different HRM practices, overall degree of HRM sophistication is low. Moreover, HRM is producing positive outcomes including diversity, better discipline, and superior performance. Some negative HRM outcomes including bureaucracy, corruption, and unnecessary control are also reported in this study. The results point towards limited sophistication of HRM function in Pakistan which needs to be increased in scope to produce more favorable outcomes.
\end{abstract}

Keywords: HRM, Recruitment, Training, Outcomes, Pakistan

\section{Introduction and Background}

HRM is capable of developing employees and enabling organizations to compete more successfully in global markets. Therefore, the demand of Globalization is pushing organization in developing countries to embrace HRM. HRM is comparatively a new field in Pakistan; however, it has gained substantial foothold during the last decade(Qayum, 2011).In Pakistan, HRM is evolved from traditional Personnel 
Management and as a consequence, many organizations have restructured their Personnel divisions and renamed it as Human Resource Divisions(Siddiqui, 1997; Khilji, 1995).Business Schools across the Universities in Pakistan have started offering Masters, MPhil, and PhD degrees in HRM and decent level of HRM related academic research is also going on in Pakistan. Despite such indicators of growth, it can be argued that the development of HRM in Pakistan is limited in nature. For example, a study by Khilji (1999a) empirically studied HRM in Pakistan and found that HRM in Pakistan is suffering from inconsistency between the policies and actual HRM practices. The same study also commented on general environment of Pakistan which characterize formal and hierarchical structure with little employee's involvement in devising HR policies and practices, centralization of HRM departments, and major communication gap between employees and HRM department. Since, there are limited studies related to the nature of HRM practices in Pakistan; therefore, the current study is conducted with a view to identify the current status of HRM in Pakistan.

\subsection{Pakistan's Brief Profile}

According to the World Bank Country Partnership Strategy Progress Report (2013), Pakistan is facing significant political, economic, and constitutional challenges. The country is experiencing militancy, sectarian violence, and natural disasters such as floods as major barriers towards development (World Bank, 2014). The reports also commented on poor Human Development record as country is lagging behind from other similar nations in terms of resource allocation for education (Currently $2 \%$ of GDP), enrollment in education, infant mortality rates, and gender disparities. Continuous economic instability is resulting in low development budgets, FDI flight, high unemployment, and uncertainty about future (Mirza, 1995; Klein, 1992).

Despite poor political, economic, and social indicators, Pakistan is showing signs of improvement. In May 2013, nationwide general elections were conducted for National and Provincial assemblies. The elections were significant because it was the first time in Pakistani history that an elected Political party (Pakistan People's Party) completed its constitutional period of five years (2008 to 2013) and handed over the government to next election winning political party. The peaceful transfer of power shows that country is restoring towards democracy and its political system is stabilizing. Similarly, according to Labor Force Survey of 2012-2013 by Federal Bureau of Statistics shows that the literacy rate is improving as literacy rate for the population above ten years of age in the country is $59.8 \%$ based on $71 \%$ for Male and $48 \%$ for female. The brief discussion about Pakistan shows that business environment in Pakistan is filled with challenges as well as some opportunities and potential for growth.

\subsection{Aims and Objectives}

The study aims to explore the current status of HRM in Pakistan while more specifically the objectives of the study are to identify the practices and the outcomes of HRM in Pakistan.

\subsection{Significance}

Most of the HRM related research is conducted in Western context while there is scarcity of HRM related research in developing countries. The literature on HRM in Pakistan is also very limited and demand greater attention from researchers. The study is 
expected to bridge the literature gap and enhance our understanding of HRM in Pakistan.

\section{Literature Review}

The following section discusses key theories and previous researches which are relevant for the current study.

\subsection{HRM in Pakistan}

Different elements of HRM include philosophy, policies, programs, practices and processes (Schuler, 1992). HRM philosophy refers to the organization's attitude towards dealing with its human resource. HRM policies on the other hand provide the link between the organization's business needs and specific people related business issues.HR practices also provide the motivation to match the specific role behavior required to reinforce the desired performance. This paper is mostly focusing on HRM practices; however, inference can be drawn about HRM philosophies and policies by looking at HRM practices.

Generally, key HRM practices include recruitment and selection, training and development, job analysis and appraisal, reward management, and health and safety (Coda et al, 2009; Buhler, 2002). In general, most Pakistani organizations are involved in these practices; however, the way these practices are performed is a matter of interest for this study. Different studies are conducted about the way HRM is practiced in Pakistan. The first significant study is conducted byKhilji\& Wang (2006) that focused on HRM practices in Pakistan. The major findings of the study are that during recruitment process candidates use contacts and influence to gain employment. Low priority is given to employee's training and appraisals interviews are mostly based on one way discussion. Often goals are difficult and handed without consulting to employees and pay is mostly not linked to performance but depends on whom an individual relates with. In other studies also conducted by Khilji (1999a, 1995), she described HRM in Pakistan at its infancy stage. Khilji threw light on organizations culture in Pakistan by highlighting features such as centralized authority, formal and hierarchical structure, low autonomy, and communication gap between management and workers. Similarly, Jamal (1998) commented that usually top level management is involved in HR related policy making while middle and lower level workers has little involvement in the process. The above mentioned studies shows that HRM in Pakistan is not much different from other developing countries as organizations face difficult external environment accompanied with centralized and bureaucratic internal culture which is causing difficulties in designing and implementing effective HRM related policies and practices.

\subsection{HRM Practices and Outcomes}

HRM practices are expected to increase the performance of individuals and organizations. Most HRM-Performance researches used HRM bundle concept which assumes that combined impact of HR Practices is more than their individual impact (Dattaet al, 2005; Huselid, 1995; Arthur, 1994). Commonly HPWS include practices such as sophisticated selection, high degree of training, flexible work arrangements, internal promotions, incentive based compensation, and information sharing (Dattaet al, 2005; Pfeffer, 1998; Huselid, 1995). A vast body of literature exist on HPWS and Performance but perhaps the most notable study on HR-Performance relationship is conducted by 
Huselid (1995). Huselid (1995) empirically showed that the use of selected HRM practices has significant effect on intermediate employee outcomes e.g. turnover, productivity, and on short and long-term measures of corporate financial performance. Similarly,Gongget al, (2009) found that there is positive relationship exists between performance oriented HR subsystem and firm performance while the relationship was mediated by middle manager's affective commitment. Snape and Redman (2010) also found a positive impact of HRM practices on organizational citizenship behaviour through an effect on perceived job influence or discretion. Overall, the literature is consistent on positive role of HRM in shaping employees behaviour and improving individual and organizational performance.

\section{Methodology}

The following section furnishes the review of research design, sampling and data collection, and data analysis for the current study.

\subsection{Research Design}

According to the Easterby et al., (1991) the leading research paradigms identified in the literature are positivism and subjectivism. Positivism paradigm views reality as objectively observable; while, subjectivism paradigm proposes to understand reality through sensation, reflection, and intuition. Subjectivism is also related to constructivism which views truth as a particular belief system held in a particular context and constructed in individual's mind (Healy and Perry, 2000). This paradigm suggests that a researcher should construct reality by interacting with different individuals(Perry et al, 1999).In the light of research objective and the constructive paradigm, it is decided to exclusively use qualitative method of data collection for this study. The decision to use qualitative method is made since qualitative methods enable researcher to gain a better initial understanding of the problem as well as opulent prospects to explore viewpoints, phenomena, attitudes, and influences (Healy \& Perry, 2000; Maxwell, 1996). Qualitative data collection method is also suitable as the prime objective of this study is to explore issues with greater details and accuracy rather than confirming a statistical relationship between different variables.

\subsection{Sampling and Data Collection}

The data was collected from HR personnel including HR Managers, HR Assistant and so on. The method of convenient sampling was utilized to gather data from HR personnel who were initially contacted through a group page of social networking website and agreed to give interviews. After initial acceptance, interviewees have been contacted in order to set schedule for interview. The profile of the interviewees is given in the table 4.1. 
Table 4.1: Demographic Characteristics of Respondents

\begin{tabular}{|c|c|c|}
\hline & Frequency & Percentage $(\%)$ \\
\hline \multicolumn{3}{|l|}{ GENDER } \\
\hline Male & 43 & $71.66 \%$ \\
\hline Female & 17 & $28.33 \%$ \\
\hline \multicolumn{3}{|l|}{ AGE GROUP } \\
\hline $20-29$ & 8 & $13.33 \%$ \\
\hline $30-39$ & 34 & $56.66 \%$ \\
\hline $40-49$ & 10 & $16.66 \%$ \\
\hline 50 and Above & 8 & $13.33 \%$ \\
\hline \multicolumn{3}{|l|}{ ROLE/STATUS } \\
\hline HR/Personnel Director & 1 & $1.66 \%$ \\
\hline HR/Personnel Officer & 45 & $75 \%$ \\
\hline HR/Personnel Assistant & 12 & $20 \%$ \\
\hline Others & 2 & $3.33 \%$ \\
\hline \multicolumn{3}{|c|}{ ORGANIZATIONAL OWNERSHIP } \\
\hline Public Sector & 13 & $21.66 \%$ \\
\hline Private Sector & 47 & $78.33 \%$ \\
\hline \multicolumn{3}{|c|}{ NATURE OF ORGANIZATIONS } \\
\hline Manufacturing & 24 & $40 \%$ \\
\hline Services & 36 & $60 \%$ \\
\hline \multicolumn{3}{|c|}{ HR RELATED WORK EXPERIENCE } \\
\hline $0-4$ Years & 8 & $13.33 \%$ \\
\hline 4.1-8 Years & 48 & $80 \%$ \\
\hline 8.1-12 Years & 2 & $3.33 \%$ \\
\hline Above 12 Years & 2 & $3.33 \%$ \\
\hline
\end{tabular}


The demographic profile of the respondents shows that most respondents were male (71\%), belonged to the age groups of 30-39 years old (56\%), and performing the duties of HR officer (75\%). Moreover, $40 \%$ respondents belonged manufacturing and $60 \%$ belonged to services sector respectively. Most respondents (80\%) had the HR related work experience between 4 to 8 years. Interview Method: Semi structured interviews were conducted from HR personnel. HR personnel are selected as suitable respondents since they are chiefly responsible for design, implementation, and evaluation of HRM policies and practice. Both face to face and phone method were used to conduct interview. Interviews were conducted in Urdu which is a national language of Pakistan and can be understood by most of the educated Pakistanis. On average, an interview took between 30 to 45 minutes. All interviews were recorded and additionally short notes were taken during the interviews.

\subsection{Interview Contents}

A semi-structured interview was developed based on the research objectives and included the following key questions accompanied by leading questions accordingly.

1. While managing human resource, how you conduct different HR practices such as HR planning, recruitment and selection, training and development, performance management, compensation management, communication, employee involvement, and so on?

2. How will you describe your work related activities in a typical working day?

3. What is your organization's HR related philosophy? Do you have formal HR policy?

4. Do you think that your organization's HR related philosophy, policy, and practices are consistent to each other?

5. In theory, HRM is supposed to produce positive outcomes for individuals, teams, units, and firm. The outcomes include attitudinal, behavioral, financial, and strategic one. Do you see any of these or other outcomes of HRM in your organization? Any specific example?

\subsection{Data Analysis}

Miles and Huberman (1994) suggest that qualitative data analysis involves three steps including data reduction, data display, and drawing conclusion. The data collected through semi structured interviews were reassessed several times in order to make sense of it. Key themes in the data were identified, noted down, and translated simultaneously. The key themes were revised in order to arrive on conclusion.

\section{Findings}

This section presents the findings of current study. As the interviews were conducted in Urdu; therefore, direct quotes are translated and reproduced here in English. Maximum efforts are taken to avoid loss of meaning in translation.

\subsection{Findings on HRM Practices}

The results show that organizations differ in terms of how they practice HRM. Table 4.2 summarizes the qualitative evidence on HRM practices. 
Table 4.2: Qualitative Evidence on HRM Practices in Pakistani Organizations

\begin{tabular}{ll} 
Qualitative Evidence & Indication \\
\hline "HR planning is not done systematically. It is very much & Poor HR Planning \\
on ad-hoc basis. Because of environmental changes and & \\
huge workload, we are unable to think much about the & \\
future" &
\end{tabular}

"Recruitment and selection process is sophisticated as well as complicated. We try our best to ensure fairness in the process. There are so many candidates who have similar credentials. Often we have to drop the exceptionally good candidates because they are not considered very suitable"

"Annual Confidential Review is used to gain support and to punish the rivals. For this reason, I don't think that the system is bringing any true results at all",

"In the past, people preferred public sector organizations because government offered job security. Now the situation is changing. Most of the government jobs are on contract. The workload is also increased and employees are expected to perform even in public sector"

"There is no Pay difference between men and women. Even in some cases, women are earning higher than men"

"Government salaries are comparatively lower. Despite over time, total salary is not much. Majority of employees have permanent jobs, therefore they can't leave their job which results in demotivated staff. Extra income by bribery is common in most government jobs and this is where they make a lot of money"

"A good portion of our time is consumed to solve conflicts. These conflicts are mostly personality based and are result of poor resource allocation and negative organizational politics. Sometimes they (conflicts) just run parallel to the organizational day to day work"

"Downsizing is common. Pakistani employees have little protection from law, therefore, terminating employees is pretty easy"

Emphasis on proper recruitment and selection

Problems in Appraisals

Changes in the nature of employment

Pay equality between gender

Job security, demotivation, and corruption in public sector organizations

The responsibility of HR to resolve conflict

Common use of downsizing

It is found that private organizations are practicing HRM more extensively as compare to the public sector organizations. Similarly, service oriented organizations are 
using more sophisticated HR practices as compare to the manufacturing organizations. Starting from HR Planning, results indicate that the sophistication of HR planning is very low. Mostly, the HR planning is done on short term basis for example organizations make HR planning at the start of particular season such as summer or winter. Mostly managers rely on past data and personal judgment for planning HR needs. The excessive workload on HR Personnel also reduces their ability to plan ahead. Results on recruitment and selection shows that generally it is considered as the most important HR related function and Pakistani HR Personnel frequently involves in recruitment and selection process. HR managers in Pakistani private sector organizations uses more sophisticated recruitment methods including internet, word of mouth, and newspaper advertisements. Interviews are commonly used during selection process which is mostly one to one basis while virtual or computer based interviews are not common. Mostly, preference is given to candidates who have qualification from reputed universities as well as candidate location is also important.

The results on job design indicate that Pakistani organizations try to follow a strict division of labor. Jobs are designed narrowly, while employees are selected based on their specializations. Employee's careers are also based on specialized areas. It is also found that training function is not very sophisticated in Pakistan. Limited training is offered in private sector organizations, which is further lower in public sector organizations. Common training method is 'On the job training', where a senior person shows a new member about how to perform certain tasks. Performance management is very much informal and practice of appraisal is limited to minority organizations. Appraisal system in public sector organizations is called Annual Confidential Review where employees have to give feedback on their colleagues without showing it to the colleague. The process is also not practiced in its true spirit.

The results on reward management indicate that Pakistani organizations offer basic salaries along with various allowances. Private sector organizations offer more incentives, more individual performance based pay, and overall more competitive salaries. On the other hand, public sector organizations offer lower salaries but offer job security, lower workload, and reliable pension plans approved and governed by the government. However, current trend indicates that reward management in public sector organizations is also becoming similar to the private sector organizations. Additionally, it is found that gender based pay differences are not common and overall the pay difference between men and women is decreasing.

The results also indicate that most of the time, HR Managers are involved in resolving conflict and handling employee grievances. Conflict between workers or between workers and managers is common and often HR managers have to handle such conflicts. Downsizing is also common and most Pakistani organizations frequently involves in it. Mass downsizing is done on the basis of mismatch between demand and supply and it is seasonal in nature. Individual employees are also terminated on the basis of negative image which is developed after some negative feedback or due to a particular incident. Downsizing or terminating in public sector organization is comparatively difficult because management have to follow a detailed and time consuming procedure in order to compliance with law. Overall, the results show that degree of sophistication of 
HRM practices in Pakistani organization is low to medium depending on the nature of organization and maturity of HRM function.

\subsection{Findings on Outcomes of HRM}

Results on the outcomes of HRM indicate that HRM in Pakistani organization is producing both favorable and unfavorable outcomes. The favorable outcomes include diversity at workplace, better discipline, and superior performance; while, the negative outcomes include more bureaucracy, corruption, and excessive control on employees. Table 4.3provides a summary of qualitative evidence related to the outcomes of HRM in Pakistani organizations.

Table 4.3: Qualitative Evidence on Outcomes of HRM in Pakistani Organizations Qualitative Evidence Indication

"The result of giving more attention to female in recruitment and selection is that workforce is more diverse now which created a favorable workplace environment. Employee's productivity, discipline, and customer service quality seems to be improving"

"HRM practices resulted in improved turnover rate and lower absenteeism. Both factors contribute in improving the operations of our organization",

"HRM has brought order in this family oriented organization. Before HRM was introduced, there were severe discipline problems. People were not following timings, leaves, or other discipline related policies. HR Department has created a sense of monitoring among employees"

"Employees in Pakistan are not easier to deal. To be a successful HR Manager, you need to be tough minded. However, the impact of HRM is significant. HR contributes in overall performance of an organization. This is something which top managers should realize soon"

"HRM Department was created in this organization about 5 years ago. Since then, positive effects such as higher productivity and profitability can be seen very clearly"

"In the past, employees related issues were dealt by general management. As part of restructuring, the organization (factory) took initiative and setup the $H R$ department. Since then, the overall functioning is disturbed. The communication, reporting, and decisions seems to be slowed down because of HR department"

"HR created an extra managerial layer between middle and top level management. Most of the communication has
Using affirmative action to increase diversity and positive effects of diversity

Positive outcomes of HRM practices including lower turnover and absenteeism

Monitoring role performed by HRM

HRM resulting in improved organizational performance

Operational problems due to the creation of HR department

Slow communication because of ISSN: 2520-0739 
HRM department

"There are conflicts and on-going politics between different departments at different levels. Even there is conflict between top management and HR therefore blocking each HR involvement other progress is norm"

"In Pakistani culture, prospective candidates for jobs are ready to pay money to become selected. I know many $H R$ Managers who even asked people to pay just for shortlisting them"

"HR has created a lot of stress for ordinary employees as now they have to provide explanations for minor issues. Employees sometimes leaves those organization where organizational politics there is strict control brought by the HR department"

The results indicate that giving attention to the HRM practices specially diversity focused practices are resulting in diverse as well as better quality staff and improved discipline which subsequently has several advantages. HRM is also contributing in improving performance level of individuals, teams, departments, and whole organization. On the other hand, the negative impact of HRM on organization is also realized by HR Personnel which includes corruption, slow decision making, and strict control affecting employees negatively. According to the respondents, taking money in return for appointing a person or promise to appoint is quite often practiced. It is a common form of corruption by HR department; however, other sources of corruptions are also utilized by HR managers such as taking money from employees in return of providing some favors. Few respondents also pointed that female prospective candidates have to face some issues due to HR Managers as some HR Managers asks prospective female candidates to go out with them or some other unsuitable favors in return of a promise that employment will be given to them.

Finally, another negative impact of HRM is the excessive monitoring and strict control of employees. According to the respondents, Pakistani managers and business owners want a strict control over employees; therefore, in such environment HR plays a role of employee's police which affects employees negatively. To become more successful, HR in Pakistan needs to promote the positive outcomes while negative outcomes should be further investigated and minimized.

\section{Discussion}

The objective of the study was to identify the current HRM practices and the perceptual outcomes of HRM in Pakistan. HR Personnel belonging to diverse organizations were interviewed in order to achieve the research objectives. The interview findings reveal that HRM practices in Pakistan are not very sophisticated. HR planning is on ad-hoc basis, while recruitment and selection is sophisticated but effected by nepotism and 'sifarish cultue'. Training activity is limited; performance management is informal; and appraisals are not properly practiced. Similarly, reward system is not well designed, and downsizing is quite common. The results are quite similar to the findings of Khilji 
and Wang (2006) who stated that HRM practices in Pakistan are not very sophisticated or properly implemented. These results are also similar to other findings for example Khilji (1999b) stated that hiring in Pakistani organization is not necessarily on merit. Moreover, she also found that Pakistani organizations is weak in employees training and career management activities and also not utilizing the services of training provider organizations. Qureshi (1995) also found that management in Pakistan has failed to develop or implement systems that are fair, led by assessment of training needs, and linked to career development plans of individual employees.

The less sophisticated level of HRM in Pakistani organizations can be explained by using Ulrich framework. Ulrich (1997) identified four key roles for HRM including administrative expert, employee champion, change agent, and strategic business partner. It seems that currently HRM in Pakistan is mostly performing the administrative role; while, other roles such as strategic business partner or employee champion role is not being performed very effectively. Thus, it is recommended that HRM in Pakistan needs to enhance the scope of activities it performs and the breadth of stakeholder's interest it serves. The findings also show that HRM in Pakistani organization is producing favorable outcomes as well as negative ones. Mostly, HRM and Performance studies focuses on the impact of HRM bundle on individual and firm performance (Snape and Redman, 2010; Gongg, et al, 2009; Harter et al, 2002; Huselid, 1995; Arthur, 1994). Instead of looking at the statistical relationships between HRM practices and individual or organizational level outcomes, the current study adopted a qualitative approach which helped in uncovering the hidden outcomes. The positive HRM outcomes (discipline, performance) are in line with outcomes found in other studies (Snapeand Redman, 2010; Gongget al, 2009; Dattaet al, 2005; Harter et al, 2002; Huselid, 1995; Arthur, 1994). The negative HRM outcomes (bureaucracy, corruption) are rarely identified in literature; however, it can be argued that these negative outcomes can be overcome by proper implementation of HRM and Management practices.

HRM, if applied properly, can be a potential source of competitive advantage for organizations (Huselid et al, 1997; Poole and Jenkins, 1996; Schuler, 1992). A strategic approach to HRM is generally characterized by linking the external and internal environment of the business to the management of HR (Baird and Meshoulam, 1988; Beer et al, 1984). These features emphasize the need to achieve consistency and complementarities among HR practices including the uniformity of practices and treatment among individuals, continuity in HR philosophy and practice, and technical complementarities among policies and practices (Baron and Kreps, 1999).Our findings indicates that despite the development of HRM departments and formal written HRM policies, still the HRM function in Pakistan is limited in scope and proving an organizational fad. A reason for this can be that despite introduction of HRM nationwide, the attitude of organization towards its employees is unchanged and many organizations cannot see the potential of its human resource. Therefore, to make HRM really working, the attitude of organizations and management needs to be changed.

\subsection{Conclusion}

It can be concluded that HRM has gained some foothold in Pakistan as organizations have created separate HRM departments and some formal HRM practices 
and policies are in place; however, the implementation and sophistication level of HRM practices is still low. Due to poor implementation of HRM which is limited in scope, the full benefits of the functions are unattained. In order to take full benefit from HRM functions, organizations as well as the top management need to give greater importance to the HRM function. HRM function itself also needs to take care of the interests of different stakeholders and assume more responsibility towards strategic planning and execution. At national level, more proactive and dynamic role from HR promoting bodies is also needed.

\subsection{Implications}

Our findings have implications for HR Personnel as well as for management and organizations. First of all, Implications for HR Personnel is that they should actively develop themselves by seeking new knowledge, improving their skills, and connecting with the latest researches in the field as such development will help them in brining growth to HRM function and tackling many HRM and work related challenges. Furthermore, HRM personnel in Pakistan that it should take a proactive approach in order to make the function and practices more sophisticated. Management and organizations need to change their attitude and philosophy of employee's management and should empower HRM department so that true benefits of HRM function can be nurtured. Without giving due attention to HRM, it will only remain a function clerical in nature, and will not contribute much in organizational competitiveness.

Researchers and practitioners are also encouraged to take a context driven approach and develop HRM practices and models which are suitable and applicable in Pakistani cultural and Institutional settings. At national level, there are certain organizations which are involved in promoting HRM such as Pakistan Society for Human Resource Management (PSHRM) and Pakistan Human Resource Network (PHRN). These organizations have some good membership base but they are not as developed as Society for Human Resource Management (SHRM) in USA, and Chartered Institute of Personnel and Development (CIPD) in UK. It is recommended that at National level these organizations should be involved in activities such as curriculum development for HR related courses, conducting exams, accreditations, research activities, and so on. These actions will result in improving the competencies of ordinary HR Personnel, enhancing the uniformity across the country and promotion of HRM at national level.

\subsection{Limitation and Directions for Future Research}

The research focused on only two aspects namely practices and outcomes while other aspects such as prospects, challenges, processes are not included in this study which remains a limitation. Some limitations also originates from the methodology and sampling procedure as a sample size and solely relying on qualitative method for data collection makes it difficult to generalize the findings. The findings of the study are also subject to the researcher's interpretation bias which also remains a limitation. A future researcher should use a larger sample drawn from organizations operating in diverse industries or sectors along with quantitative methods to collect and analyze data. A future research should also link the topic with convergence or divergence discussion and assess the HRM practices in Pakistan by issue of effects of Pakistani national culture on HRM. 


\section{References}

Arthur J. B. (1994). Effects of human resource systems on manufacturing performance and turnover. Academy of Management Journal 37, 670-687.

Baird, L. \& Meshoulam, I. (1988). Managing the two fits of Strategic Human Resource Management. Academy of Management Review 13, 116-128.

Baron, J. N. \& Kreps, D. M. (1999). Consistent Human Resource Practices. California Management Review 41, 29-53.

Beer, M., Spector, B., Lawrence, P. R., Mills, D. Q. \& Walton, R. E. (1984). Managing Human Assets. Free Press: New York.

Buhler, P. (2002). Human Resource Management. Massachusetts: Avon.

Coda, R., Cesar, A. Bido, D. S, \& Louffat, E. (2009). Strategic HR? A Study of the Perceived Role of HRM Departments in Brazil and Peru. Brazilian Administrative Review 6(1), 15-33. [Online] Available from http://dx.doi.org/10.1590/S1807-76922009000100003

Datta D. K., Guthrie J. P., \& Wright P. M. (2005). Human Resource Management And Labour Productivity: Does Industry Matter? Academy of Management Journal48, 135-145.

Easterby, M., Thorpe, R. \& Lowe, A. (1991). The Philosophy of Research Design, Management Research;An Introduction. London: Sage Publications.

Gong, Y., Law, K. S., Chang, S. \& Xin, K. R. (2009). Human Resource Management and Firm Performance: The Differential Role of Managerial Affective and Continuance Commitment. Journal of Applied Psychology94, 263-275.

Harter, J., Schmidt, F. \& Hayes, T. (2002). Business Unit Level Relationship between Employee Satisfaction, Employee Engagement and Business Outcomes: A Metaanalysis. Journal of Applied Psychology 87, 268-279.

Healy, M. \& Perry, C. (2000). ComprehensiveCriteria to Judge Validity and Reliability of Qualitative Research within the Realism Paradigm, Qualitative Market Research.An International Journal 3(3), 118-126.

Huselid, M. A., Jackson, S. E. \& Schuler, R. S. (1997). Technical and Strategic Human Resource Management Effectiveness as Determinants of Firm Performance. Academy of Management Journal 40, 171-188.

Huselid, M. A. (1995). The Impact of Human Resource Management Practices on Turnover, Productivity, and Corporate Financial Performance. Academy of Management Journal 38, 635-672.

Jamal, A. (1998). Can We Learn Something from the Perceptions and Consumption Practices of Transnational South Asia Communities Living in the West? Paper presented at the Inaugural Conference of Asia Academy of Management, Hong Kong.

Khilji, S. \& Wang, X. (2006). Intended and Implemented HRM: The Missing Linchpin in Strategic Human Resource Management Research. International Journal of HRM 17(7), 1171-1189

Khilji, S. E. (1995). International Human Resource Management in Pakistan. unpublished MPhil thesis, University of Cambridge. 
Khilji, S.E. (1999a). An Empirical Study of Human Resource Management in Pakistan: The Case of Pakistan. unpublished PhD Thesis, University of Cambridge.

Khilji, S.E. (1999b). Management in Pakistan. In Warner, M. (eds.).International Encyclopedia ofBusiness and Management. London: International Thomson

Klein, M. (Ed). (1992). Commercial Banking in Pakistan. Karachi: LUMS.

Maxwell, J. A. (1996) Qualitative Research Design: An Interactive Approach. London: Sang.

Miles, M. \& Huberman, A. (1994). Qualitative Data Analysis.2nd Edition, Thousand Oaks, CA: Sage Publications.

Mirza. (1995). Privatization in Pakistan. Lahore, Pakistan: Ferozesons.

Pakistan Bureau of Statistics. (2013). Labor Force Survey. [Online] Available fromhttp://www.pbs.gov.pk/content/labour-force-survey-2012-13-annual-report

Perry, C., Riege, A. \& Brown, L. (1999). Realism Role among Scientific Paradigms in Marketing Research. Irish Marketing Review, 12(2), 16-23.

Pfeffer, J. (1998). The Human Equation: Building Profits by Putting People First. Boston, MA: Harvard Business School Press.

Poole, M. \& Jenkins, G. (1996). Competitiveness and Human Resource Management Policies. Journal of General Management 22, 1-19.

Qayum, A. (2011) HRM: Does It Matters, Pakistan today. [Online] Available fromhttp://www.pakistantoday.com.pk/2011/01/18/ comment/editors-mail/hrmdoes-it-matter

Qureshi, Z.A. (1995). Impact of Management Practices on Employee Effectiveness in South Asia.In Kanungo, R.N. (ed.).New Approaches to Employee Management,London: JAI Press,

Schuler, R. S. (1992). Strategic Human Resources Management: Linking the People with the Strategic Needs of the Business.Organizational Dynamics 21, 18-32.

Siddiqui, H. R. (1997). Human Resource Development in Pakistan. Dawn, Karachi. $23^{\text {rd }}$ March 1996.

Snape E. \& Redman, T. (2010). HRM Practices, Organizational Citizenship Behaviour, andPerformance. Journal of Management Studies47, 1219-1247

Ulrich, D. (1997). Human Resource Champions. Boston, MA: Harvard Business School Press.

World Bank. (2013). Country Partnership Strategy Progress Report. [Online] Available from, http://www.worldbank.org/en/results/ 2013/04/26/pakistan-achievingresults-in-a-challenging-environ ment

World Bank. (2014). Country Overview of Pakistan. [Online] Available from http://www.worldbank.org/en/country/pakistan/overview\#3 